\title{
PENGARUH PENERAPAN LATIHAN GERAKAN ROM (RANGE OF MOTION) TERHADAP KEKUATAN OTOT PASIEN PASCA STROKE ISKEMIK
}

\author{
Sri Kurnia Dewi ${ }^{1 *}$, Lutiyah ${ }^{2}$ \\ 1-2Universitas Muhammadiyah Sukabumi \\ Email Korespondensi: srikurniadewi484@ummi.ac.id \\ Disubmit: 22 Januari 2022 Diterima: 23 Januari 2022 Diterbitkan: 01 Februari 2022 \\ DOI: https://doi.org/10.33024/mnj.v5i2.5884
}

\begin{abstract}
THE EFFECT OF APPLICATION ROM (RANGE OF MOTION) MOVEMENT EXERCISES ON THE MUSCLE STRENGTH OF POST ISCHEMIC STROKE PATIENS
\end{abstract}

Intoduction : Range of Motion Exercise in an exercise performed to evaluate and improve the function of the musculoskeletal system and is olso one of therapy in stroke patients that aims to increase cerebral blood flow, minimiza disability caused by stroke, so as to refine sensory motoric function.

Purpose : the purpose of this resea is to identify the effect of Range of Motion Exercise to the muscle strength of iskemic stroke patients in Neuroligy Department of General Hospital RSUD Cimacan.

Method : This study is aquasi experiment with methods Nonequivalent Control Group Design. The sampling technique that used is purposive sampling. Primary data gain from patient observation sheets and secondary data from the medical records of patiennt treated at Neurology Departement og General Hospital RSUD Cimacan. This study involving 15 respondents in the research period Oktober, 2021 - February 2022 and was carried out in the room Neuro RSUD Cimacan.

Results :the analysis by using a Paired Sampel $T$ test statistic-Test with significance level (a) 0.05, shows scores and muscle strength before and after done the exersice range of motion have elevated the score avarage of 3.87. The influence of practice range of motion of muscle strength in patients with stroke value of $P=0.003$.

Conclution :The conclusion that can be drawn from this study is that there in an affect of range of motion exercise on muscle strength in stroke patients in the neurology room of RSUD Cimacan.

Keywords: Stroke, ROM and Muscle of Power 


\section{INTISARI:PENGARUH PENERAPAN LATIHAN GERAKAN ROM (RANGE OF MOTION)TERHADAP KEKUATAN OTOT PASIEN PASKA STROKE ISKEMIK}

Latar Belakang: Latihan Range of Motiom merupakan kegiatan Latihan yang dapat menentukan nilai dan mengetahui peningkatan fungsi sistem musculoskeletal dan bisa juga menjadi bagian dari terapu lanjutan penderita stroke yang dapat meningkatkan aliran darah otak, serta mengurangi kondisi cacat, dan mampu mengembalikan fungsi sensori motorik.

Tujuan: Tujuan dari penelitian ini adalah mengidentifikasi pengaruh Latihan Range Of Motion terhadap kekuatan otot pasien paska stroke iskemik.

Metode: Metode yang digunakan yaitu quasi eksperimen dan nenoguivalent control group desain. Sampling menggunakan Surposive sumpling. Data primer didapat dari lembar hasil observasi pasien dan data sekunder didapat dari rekam medis pasien yang dirawat yang dirawat di ruang neurologi RSUD Cimacan. Sample dalam penelitian ini melibatkan 15 responden dengan rentang waktu antara bulan oktober 2021 - Februari 2022 dan dilakukan di ruang neurologi RSUD Cimacan.

Hasil: Analisa dengan menggunakan uji statistic Paired sample T-Test dengan tingkat kemaknaan (a) 0.05 , menunjukan kekuatan otot sebelum dan sesudah dilakukan Latihan Range Of Motion mengalami peningkatan score rata-rata 3.87. Kesimpulan : Kesimpulan yang dapat ditarik dari penelitian ini ialah ada pengaruh latihan range of motion terhadap kekuatan otot pada pasien stroke di ruang neurologi RSUD Cimacan.

Kata Kunci: Stroke, ROM dan Kekuatan Otot

\section{PENDAHULUAN}

Stroke merupakan hambatan kesehatan yang mengancam dan semakin banyak didunia terutama negara berkembang yang menjadi penyumbang angka kejadian stroke di dunia. Secara total, sekitar 80 juta orang telah menderita stroke pada waktu yang sama. Menurut organisasi kesehatan dunia, “diperkirakan 15 juta orang diseluruh dunia menderita stroke, dimana sekitar 5 juta menderita cacat permanen" (Suryani 2008). American Heart Association (AHA) menunjukan bahwa ada stroke di Amerika Serikat hamper setiap 45 menit, stroke menempati urutan ketiga dibawah penyakit jantung dan kanker. menurut Adams Et Al (2004), "setiap tahun 500.000 orang Amerika menderita stroke, 400,000 menderita stroke iskemik, 100.000 menderita stroke hemorogik, dan 175.000 di antaranya meninggal. Di Inggris, sekitar 250.000 menderita stroke". Sementara itu, studi kesehatan daerah yang dilakukan oleh Kementerian Kesehatan Republik Indonesia pada tahun 2011 dalam laporannya menemukan bahwa di Indonesia, 8 dari setiap 1.000 orang mungkin mengalami stroke. Stroke adalah penyebab utama kematian di antara orangorang dari segala usia, terhitung $15,4 \%$. Dari tujuh kematian yang ditemukan di Indonesia, satu disebabkan oleh stroke (Depkes RI, 2011). Menurut Yayasan Stroke Indonesia, “Jumlah stroke di Indonesia pada periode terakhir terus meningkat". Data yang diperoleh di tempat kejadian 
menunjukkan bahwa kejadian stroke meningkat pesat seiring bertambahnya usia. Dari usia 35, dari usia 10 , risiko stroke meningkat lebih dari dua kali lipat. Hampir $5 \%$ penduduk di atas 65 tahun pernah mengalami setidaknya satu kali stroke, menurut data prevalensi hipertensi di Indonesia proporsinya sekitar 95\%. Ahli epidemiologi memperkirakan bahwa sekitar 12 juta penduduk Indonesia yang berusia di atas 35 tahun saat ini dan di masa depan berisiko terkena stroke (Yastroki, 2011). Menurut data yang diperoleh Departemen Neurologi RSUD Cimacan, terdapat 69 pasien stroke sejak Oktober hingga Desember 2020. Terdapat 16 kasus stroke hemoragik dan 53 kasus stroke iskemik. Menurut penelitian tahun 2013 oleh Herin Mawarti dan Farid tentang pengaruh latihan ROM pasif (Range Of Motion) terhadap peningkatan kekuatan otot pada pasien stroke, terbukti bahwa latihan ROM pasif berpengaruh signifikan terhadap peningkatan kekuatan otot pada pasien stroke. pasien menderita kekuatan otot. Keseimbangan dan koordinasi motorik terganggu, dan sulit berjalan, serta sulit melakukan aktivitas sehari-hari. Aktivitas motorik dapat mempercepat pemulihan pasien stroke karena mempengaruhi sensasi motorik otak (Irdawati, 2008). Melihat banyaknya pasien stroke yang menjalani pengobatan, terlihat kondisi otot pasien stroke biasa yang lemah. Meski ada ruang rehabilitasi di rumah sakit, tidak ada jadwal yang jelas apakah petugas rehabilitasi akan datang ke ruangan atau membawa pasien ke ruang rehabilitasi untuk latihan mobilitas sendi. Berdasarkan kondisi tersebut, saya tertarik untuk melakukan penelitian untuk memberikan latihan range of motion (ROM) pada pasien stroke di bangsal saraf RSUD Cimacan.

\section{METODE PENELITIAN}

Sifat penelitian ini adalah metode kuasi eksperimen nonequivalent control group design method. Siapkan grup Pre-Post Test, dan evaluasi atau ukur grup sebelum grup tanpa grup kontrol diuji. Selanjutnya dilakukan uji coba kelompok dan dilakukan penilaian kembali setelah uji coba kelompok (Suryanto, 2011).

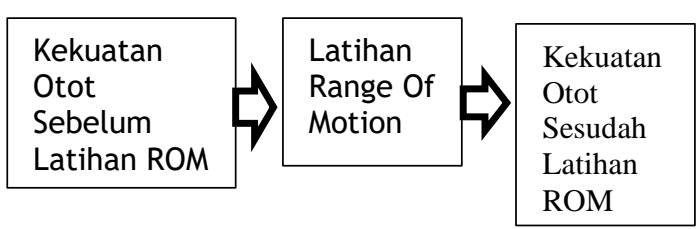

Penelitian dilaksanakan di Bagian Neurologi RSUD Cimacan dari bulan Oktober 2021 sampai dengan bulan Februari 2022. Metode pengambilan sampel menggunakan purposive sampling, yaitu pengambilan sampel berdasarkan pertimbangan peneliti sendiri dan kasus yang ditemukan pada saat itu, dengan jumlah narasumber sebanyak 15 orang. Kriteria inklusi adalah seluruh pasien stroke iskemik yang dirawat di bangsal saraf RSUD Cimacan kemudian ingin menjadi responden. Tingkat kognitif Compos Mentis menjadi serangan 2-3 hari untuk pasien stroke iskemik. Kriteria eksklusi adalah semua pasien stroke rawat jalan, pasien koma, dan penyakit sendi (atrofi, 
rigiditas dan dislokasi). Instrumen yang digunakan untuk pengumpulan data dalam penelitian ini adalah tabel observasi latihan rentang gerak dan kekuatan otot. Pada tahap awal penelitian, peneliti memperoleh surat izin dari lembaga UMMI, kemudian peneliti memperoleh data sekunder dari data Bagian Rekam Medis RSUD Cimacan. Penelitian akan dilakukan secara bertahap, dimulai dengan pengenalan peneliti, melakukan penyelidikan pendahuluan, dan penetapan sampel berdasarkan kriteria inklusi dan eksklusi. Melakukan observasi pendahuluan (pre-test), dengan mengukur kekuatan otot pasien, kemudian melakukan latihan amplitudo latihan, 5 kali sehari, 10 menit setiap kali, total 8 latihan. Kemudian Anda dapat melihat apakah pengamatan akhir (posttest) memiliki pengaruh rentang gerak terhadap kekuatan otot pasien. Mengumpulkan data dari hasil yang diisi oleh narasumber, kemudian mengolahnya melalui tahapan editing, coding, cleaning, tabulation dan lainnya. Gunakan analisis univariat dan analisis bivariat untuk analisis data, menekankan etika keperawatan dari informed consent, anonimitas, dan kerahasiaan.

\section{HASIL PENELITIAN DAN PEMBAHASAN \\ Data diambil melalui} observasi langsung pada respon dan untuk mencari data pre test dan post test. Sebelumnya pasien diukur tingkat kekuatan otot nya, setelah itu responden diberi latihan range of motion 5 kali sehari dalam waktu 10 menit dan dilakukan sebanyak 8 harilatihan. Selanjutnya akan diukur kembali tingkat kekuatan otot nya. Karakter responden terdiri dari jenis kelamin, umur, pekerjaan.

\section{Analisis Univariat}

Tabel1.

Distribusi Responden Berdasarkan Jenis Kelamin di ruang nerologi RSUD Cimacan Tahun 2022.

\begin{tabular}{ccc}
\hline Jenis Kelamin & $\mathbf{N}$ & $\%$ \\
\hline Laki-laki & 10 & 66,7 \\
Perempuan & 5 & 33,3 \\
\hline Total & 15 & 100 \\
\hline \multicolumn{2}{c}{ Sumber : data primer }
\end{tabular}

Tabel 2.

Distribusi Responden Berdasarkan Umur di ruang nerologi RSUD Cimacan Tahun 2022.

\begin{tabular}{ccc}
\hline $\begin{array}{c}\text { Umur } \\
\text { (Tahun) }\end{array}$ & $\mathbf{N}$ & $\%$ \\
\hline$<40$ & 2 & 13,3 \\
-60 & 7 & 46,7 \\
$>60$ & 6 & 40,0 \\
\hline Total & 15 & 100 \\
\hline \multicolumn{3}{c}{ Sumber : data primer }
\end{tabular}


Tabel 3.

Distribusi Responden Sebelum Dilakukan Latihan Range Of Motion di ruang nerologi RSUD Cimacan Tahun 2022.

\begin{tabular}{ccccc}
\hline $\begin{array}{c}\text { Kekuatan } \\
\text { Otot } \\
\text { Sebelum } \\
\text { ROM }\end{array}$ & F & $\%$ & $\begin{array}{c}\text { Valid } \\
\text { Precen } \\
\mathbf{t}\end{array}$ & $\begin{array}{c}\text { Cumula } \\
\text { tive } \\
\text { Precent }\end{array}$ \\
\hline 40 & 1 & 6.7 & 6.7 & 6.7 \\
\hline 44 & 1 & 6.7 & 6.7 & 13.3 \\
\hline 48 & 2 & 3.3 & 3.3 & 26.7 \\
\hline 57 & 1 & 6.7 & 6.7 & 33.3 \\
\hline 58 & 3 & 20.0 & 20.0 & 53.3 \\
\hline 60 & 2 & 13.3 & 13.3 & 66.7 \\
\hline 62 & 2 & 13.3 & 13.3 & 80.0 \\
\hline 63 & 1 & 6.7 & 6.7 & 86.7 \\
\hline 64 & 2 & 13.3 & 13.3 & 100.0 \\
\hline Total & 15 & 100.0 & 100.0 \\
\hline \multicolumn{5}{c}{ Sumber $:$ data primer } \\
\hline \multicolumn{4}{c}{}
\end{tabular}

Tabel4.

Distribusi Frekuensi Responden Sesudah Dilakukan Latihan Range Of Motion di ruang nerologi RSUD Cimacan Tahun 2022.

\begin{tabular}{|c|c|c|c|c|}
\hline $\begin{array}{l}\text { Kekuatan } \\
\text { Otot } \\
\text { Setelah } \\
\text { ROM }\end{array}$ & $F$ & $\%$ & $\begin{array}{l}\text { Valid } \\
\text { Precent }\end{array}$ & $\begin{array}{l}\text { Cumul } \\
\text { ative } \\
\text { Precen } \\
t\end{array}$ \\
\hline 38 & 1 & 6.7 & 6.7 & 6.7 \\
\hline 40 & 1 & 6.7 & 6.7 & 13.3 \\
\hline 46 & 2 & 13.3 & 13.3 & 26.7 \\
\hline 62 & 2 & 13.3 & 13.3 & 40.0 \\
\hline 65 & 2 & 13.3 & 13.3 & 53.3 \\
\hline 66 & 2 & 13.3 & 13.3 & 66.7 \\
\hline 68 & 2 & 13.3 & 13.3 & 80.0 \\
\hline 70 & 2 & 13.3 & 13.3 & 93.3 \\
\hline 72 & 1 & 6.7 & 6.7 & 100 \\
\hline Jumlah & 15 & 100 & 100 & \\
\hline
\end{tabular}


Tabel 5. Pengaruh Penerapan Latihan Gerakan Rom (Range Of Motion) Terhadap Kekuatan Otot Pasien Pasca Stroke Iskemik

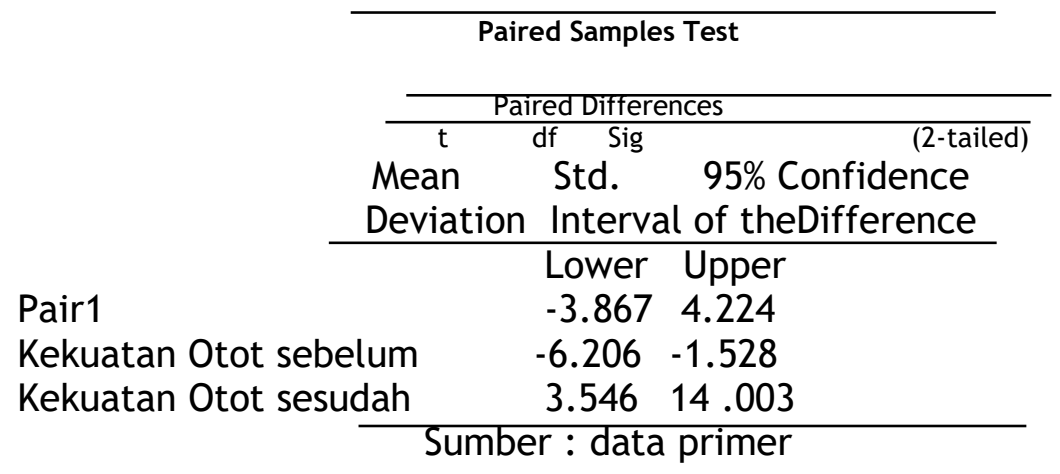

\section{PEMBAHASAN}

\section{Karakteristik Responden}

Kepribadian nara sumber dalam penelitian ini terdiri dari umur, jenis kelamin dan pekerjaan Penelitian yang dilakukan di bangsal saraf RSUD Cimacan diperoleh 15 orang yang diwawancarai yang terdiri dari 10 laki-laki $(66,7 \%)$ dan 5 laki-laki (33,3\%). Siapa perempuan. Hal ini sesuai dengan pernyataan Feigin (2007) dalam bukunya "Stroke" bahwa laki-laki memiliki risiko terkena stroke $20 \%$ lebih tinggi daripada perempuan, yang mungkin berhubungan dengan kecenderungan laki-laki untuk merokok dan minum. Stroke hemoragik dan non hemoragik Narasumber dalam penelitian ini berusia 18-78 tahun. Kelompok umur dibagi menjadi 3 kelompok, yaitu 2 orang $(13,3 \%)$ di bawah 40 tahun, 7 orang berusia 41-60 tahun $(46,7 \%)$, dan 6 orang berusia $>60$ tahun $(40,0 \%)$. Risiko stroke meningkat sejak usia 45 tahun. Setelah mencapai usia 50 tahun, Setelah mencapai usia 50 tahun, risiko stroke meningkat $11-20 \%$ setiap 3 tahun, dan meningkat seiring bertambahnya usia (Feigin, 2007). Pada orang di bawah usia 40 tahun disebabkan oleh jenis penyakit arteri tertentu, adanya tumor otak, penggunaan koagulan oral, amfetamin, berbagai aditif dan kontrasepsi oral (Smeltzer dan Bare, tahun 2002).

Gambaran Kekuatan Otot Sebelum dan Sesudah Dilakukan Latihan Range Of Motion.

Menurut pelaksanaan latihan kegiatan, 15 pasien bersedia untuk diwawancarai. Menurut Syahmirza Indah Lesmana dalam Pelatihan Keperawatan Fisioterapi Lampung II (Juni 2002), ada beberapa faktor yang mempengaruhi pelaksanaan rentang aktivitas, seperti jenis kelamin, usia, rentang rentang aktif dan rentang pasif. Menurut hasil observasi setelah 5 latihan ROM dalam 10 menit sehari, setelah 8 repetisi terjadi peningkatan yang signifikan.

meskipun waktu dan lama penelitian berbeda, rentang gerak memiliki dampak pada kekuatan otot pasien stroke. Hasil penelitian (Febrina Sukma Ningrum, 2011) dilakukan selama 7 hari dan mendapat 2 kali perawatan sehari, dengan sampel sebanyak 20 orang yang diwawancarai, dan penggunaan tes yang sudah ada menunjukkan rata-rata peningkatan kekuatan otot antara sebelum dan 7 hari setelah intervensi.Ruang adalah 1,70. Sama seperti penelitian pada (Mawarti \& Farid, 2013), penelitian dilakukan selama 
7 hari, mendapat 2 kali perlakuan sehari, dan diambil sampel oleh 17 orang yang diwawancarai.

Teknik purposive sampling menunjukkan bahwa ada perbedaan kekuatan otot sebelum dan sesudah. Setelah menggunakan enzim semi-parsial dengan sig = 0,000 untuk latihan ROM pasif. Menurut Guyton (2007), mekanisme kontraksi dapat meningkatkan otot polos pada ekstremits. Latihan ROM pasif dapat menimbulkan rangsangan, sehingga meningkatkan aktivasi neuromuskular dan kimia otot. Rangsangan neuromuskular akan meningkatkan rangsangan serabut saraf otot tungkai terutama saraf parasimpatis merangsang produksi asetilkolin yang menyebabkan terjadinya kontraksi. Melalui mekanisme otot terutama otot polos tungkai akan meningkatkan metabolisme kartilago posterior dan menghasilkan ATP yang digunakan oleh otot polos tungkai sebagai energi kontraksi untuk meningkatkan tegangan otot polos tungkai. anggota badan. Pengaruh latihan ROM terhadap kekuatan otot pasien stroke ditentukan dengan melihat hasil penelitian dan hasil uji $\mathrm{T}$, serta diperoleh pengaruh nilai rata-rata sebelum dan sesudah perlakuan. Hasil penelitian ini memperkuat upaya pemberian asuhan pada pasien stroke yang terdiagnosis asuhan terkait gangguan aktivitas fisik. Menderita hemiplegia/hemiplegia (padila, 2012). Salah satu intervensi keperawatan yang dapat dilakukan adalah perawat menggunakan latihan rentang gerak pasif yang melibatkan pasien dan keluarganya sehingga mendapatkan hasil yang terbaik.

\section{KESIMPULAN}

Kesimpulan yang dapat ditarik dari penelitian ini ialah ada pengaruh latihan range of motion terhadap kekuatan otot pada pasien stroke di ruang neurologi RSUD Cimacan.

\section{DAFTAR PUSTAKA}

Adams, et al. (2007). American of Academy of Neurology affirms the value of this guide line asan Quality of Care Outcomes in Research Interdisciplinary Working. Groups. Stroke

Brunner., Suddarth. (2008). Keperawatan Medikal - Bedah. Jakarta : EGC.

Depkes RI. (2011). http://www.depkes.go.id/ind ex.php/berita/press -release/ 1703-8-dari-1000-orang-diindonesia-terkena stroke. html di akses tanggal 13 Mei 2013 jam 05.20 WIB.

Febrina, Sukmaningrum. (2011). http://ejournal.stikestelogore jo.ac.id/index.php/ilmukeper awatan/article di akses tanggal 09 juni 2013 jam 00.25 WIB.

Suryani. (2008). Gejala Stroke tidak hanya lumpuh. http: //m.suaramerdeka.com. di akses tanggal 20 mei 2013 jam10.30 WIB.

Suryanto. (2011). Metodologi dan Aplikasi Penelitian Keperawatan.Yogyakarta: Nuha Medika.

Smeltzer\& Bare. (2002). Buku ajar Keperawatan medical bedah Brunner \& Suddarth vol. 1 (Andry Hartono, penerjemah). Jakarta: EGC

Guyton, Arthur C. (2007). Buku Ajar Fisiologi Kedokteran. Jakarta: EGC.

Irdawati,(2008). http://ejournal.undip.ac.id/i ndex.php/ 
$\mathrm{mmi} /$ article/view/di akses tanggal 05 mei 2013 jam 08.00 WIB.

Mawarti \& Farid, (2013) http://www.journal.unipdu.a c.id/inde x.php/eduhealth/article/ di akses 09 juli 2013 jam 00.40 WIB.

Padila, (2012). Keperawatan Medikal Bedah. Yogyakarta. Nuha Medika.

Yastroki.

http://www.yastroki.or.id/re ad.php?i d=340di akses tanggal 07 mei 2013 jam 11.00 WITA. 